\title{
OVARIAN ECTOPIC PREGNANCY A REPORT OF TWO CASES
}

\author{
Faisal Basama, MRCOG
}

There were 11 maternal deaths from ectopic pregnancy in the last report of the Confidential Enquiries into Maternal Deaths And Child Health ${ }^{(1)}$, ranking ectopic pregnancy as the fourth leading cause of direct maternal deaths. In none of the reported cases was the diagnosis made before rupture of the ectopic pregnancy and six of these direct deaths had some form of substandard care.

Faisal Basama, specialist registrar in obstetrics and gynaecology at the Royal Lancaster Infirmary, describes his experience of a particular presentation of ectopic pregnancy.

\section{INTRODUCTION}

Ectopic pregnancy is a major cause of maternal morbidity and mortality. Its incidence is increasing, with nearly 32,000 cases diagnosed within three years in the United Kingdom; an incidence of $11.1 / 1000$ pregnancies $^{(2)}$. Between 2.6-3.3\% of these are the variant ovarian ectopic pregnancy ${ }^{(23,45.6)}$. There is high expectation of earlier diagnosis of all ectopics, especially ovarian ectopic pregnancy, owing to the availability of quantitative measurements of Beta human Chorionic Gonadotrophins ( $\beta \mathrm{hCG}$ ) and transvaginal ultrasonography. Despite the increased awareness, however, ovarian ectopic pregnancy is still difficult to diagnose $\mathrm{e}^{(5.6)}$. It is not uncommon that the suspicions of an ovarian ectopic pregnancy first arise on the operating table and that the final diagnosis could only be made by histopathology $y^{(4)}$.

These two case reports demonstrate that despite the clear preoperative transvaginal demonstration of a suspicious echogenic adnexal mass that was inseparable from the ovary, the diagnosis of ovarian ectopic pregnancy rested, primarily, on histological examination of the surgically removed tissues.

\section{Case 1}

A 37-year-old lady presented with seven weeks plus two days amenorrhoea, brownish vaginal discharge and right side lower abdominal pain. She had two Caesarean deliveries. A urine pregnancy test was positive. She was haemodynamically stable.

The clinical examination revealed a tender, palpable mass in the right iliac fossa of approximately $5 \times 3 \times 3$ centimetres. A transvaginal ultrasound scan showed a bulky, empty uterus, small amount of free fluid in the pouch of Douglas and a right adnexal mass, measuring 5.1 $3.6 \times 2.9$ centimetres, which could not be demonstrated separate from the right ovary. Ectopic pregnancy was highly suspected.

The routine investigations were normal. At laparoscopy the uterus, the tubes and left ovary were normal. The right ovary was lying posterior to the uterus and adherent to the large bowel. There was active bleeding from the ovary; approximately 300 millilitres of blood were found in the peritoneal cavity. There was no obvious ectopic pregnancy. The initial impression was that of spontaneous miscarriage and ruptured ovarian cyst. Midline omental adhesions were noticed. The procedure proceeded to laparotomy. All the tissues and debris from the right ovary were removed by dissection forceps and sent for histological examination. Haemostasis was achieved by thermal coagulation. Subsequent histopathology revealed ovarian ectopic pregnancy, when first trimester villi were demonstrated.

The woman had an uneventful postoperative period. The level of serum $\beta$ hCG returned back to normal after two weeks.

Case 2

A 30-year-old lady presented with five weeks plus two days amenorrhoea, brownish vaginal discharge and right side lower abdominal pain. She had two normal vaginal deliveries. She had no past medical or surgical history. A urine pregnancy test was positive.

The clinical examination was normal. She had an intra uterine contraceptive device (IUCD) in-situ. A transvaginal ultrasound scan showed a thickened endometrium, measuring $15 \mathrm{~mm}$, with an IUCD in-situ. There was no adnexal pathology or free fluid in the pouch of Douglas. In view of the empty uterus a serum $\beta$ hCG level was requested; the initial level of the $\beta$ hCG was 813 units and in 48 hours it rose to 2249 units. A pelvic ultrasound scan was planned for the following morning, but she was admitted to the hospital on the same night complaining of abdominal pain, which was followed by passage of blood, blood clots and some tissues. There were no definite products of conception. She was tender on abdominal and bimanual examinations. A repeat transvaginal ultrasound scan showed similar findings to the first scan; this time, however, there was a moderate amount of fluid in the pouch of Douglas. Laparoscopy was advised, which revealed bulky uterus, normal tubes and normal left ovary. There was active bleeding from the right ovary with approximately 50 millilitres of blood in the peritoneal cavity. There was no obvious ectopic pregnancy. It was thought that the woman had spontaneous miscarriage and a ruptured ovarian cyst. Blood, blood clots, all the tissues and debris from the right ovary were removed laparoscopically and sent for histological examination. Haemostasis was secured by thermal coagulation.

Syncytiotrophoblast ovarian ectopic pregnancy was diagnosed on histopathological examination of the retrieved specimens. Serial estimations of serum $\beta$ hCG were arranged; the level rose to $10076 \mathrm{iu}$ in one week. Another transvaginal scan showed thick decidual reaction, separation of the endometrium and fluid in the uterine cavity.

In view of the $\beta$ hCG levels and the scan findings an active ovarian ectopic pregnancy was highly suspected. A laparotomy was performed and a right ectopic pregnancy was confirmed. The ectopic tissue was excised and the ovary was repaired. 


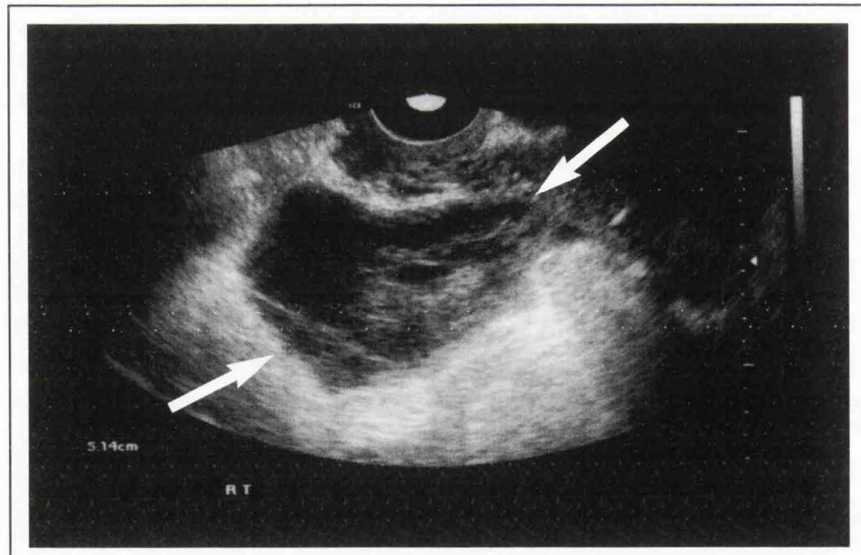

A large amount of fluid can be seen in the pouch of Douglas with a mixed echogenic mass, inseparable from the right ovary; it measures $5.14 \times 3.6 \times 2.86$ centimetres

The woman had an uneventful postoperative period Serum $\beta$ hCG level returned back to normal after three weeks The histology of the tissues removed confirmed the diagnosis of ovarian ectopic pregnancy.

\section{DISCUSSION}

Preoperative diagnosis of ovarian ectopic pregnancy is difficult because the symptoms and signs are similar to those of tubal pregnancy or a ruptured corpus luteum cyst patients may have amenorrhoea, irregular vaginal bleeding, abdominal pain and adnexal mass ${ }^{(5,6)}$. Improved ultrasound resolution and transvaginal sonography have significantly facilitated adnexal imaging. A study in 1997 showed that transvaginal ultrasonography is of diagnostic value in differentiating an ovarian ectopic pregnancy from a tubal ectopic pregnancy ${ }^{(7)}$. In these two cases, however, though preoperative transvaginal ultrasonography has demonstrated suspicious echogenic adnexal mass that was inseparable from the ovary, the diagnosis of ovarian ectopic pregnancy was only confirmed on histopathology.

Increased vascularity of the ovarian tissue and the growing gestation sac usually results in rupture of the ovary and haemoperitoneum ${ }^{(4.6)}$. In these two cases the laparoscopy revealed intact fallopian tubes with ruptured haemorrhagic ovarian cyst and haemoperitoneum; hence a laparotomy was required.

At time of surgery we found it difficult to differentiate between an ovarian pregnancy and a bleeding ruptured corpus luteum, perhaps as difficult as to localise an intact ovarian pregnancy ${ }^{(8)}$. Retrospectively, our initial diagnosis of miscarriage and ruptured ovarian cyst was erroneous; a problem noticed by other investigators ${ }^{(5)}$. Definitive diagnosis of ovarian ectopic pregnancy rests on histopathology ${ }^{(8,45)}$.

Medical management of ovarian ectopic pregnancy has been reported ${ }^{(9)}$. It is difficult, however, to diagnose ovarian pregnancy without surgery and histopathology. Seinera believes that if laparoscopy is required for diagnosis, definitive surgical management may be accomplished at the same time ${ }^{(5)}$. The role of medical treatment remains undefined. It may, however, have some role with a primary incomplete resection and persisting trophoblastic tissue ${ }^{(10)}$.

These two cases are possibly primary ovarian ectopic pregnancies as both met the first three of a series of criteria outlined by Spiegelberg ${ }^{(11)}$ in 1878 .
Spiegelberg's postulates for overian ectopic pregnancy:

1. The fallopian tubes should be intact and separate from the ovary.

2. The gestational sac should occupy the normal position of the ovary.

3. The gestational sac should be connected to the uterus by the uterine ovarian ligament.

4. Ovarian tissue must be present in the specimen attached to the gestational sac.

\section{Seinera's ${ }^{(5)}$ modification of the fourth postulate:}

4. Detection of chorionic villi without concurrent detection of an intact ovarian parenchyma.

Only the second case fulfilled the fourth criteria under the original Spiegelberg postulates, but the modification by Seinera allows both to be included.

Operative advances and early diagnosis have led to increased therapeutic laparoscopies and more conservative ovarian surgery than in the past ${ }^{(8.5)}$. We did not resect the ovary in the first case and during the initial laparoscopy in the second case. The volume of the tissue, retrieved by dissection forceps, might have been insufficient; hence the fourth postulate of Spiegelberg was not met. Because it is more important to preserve the follicular activity of the ovary and there is little justification to expand the surgical procedure beyond the removal of the gestational $\mathrm{sac}^{(5)}$ and because the distinction between primary and secondary ovarian pregnancy is of academic interest and has no therapeutic relevance, Seinera has suggested that the fourth postulate of Spiegelberg should be modified $^{(5)}$.

Two unknown questions concerning ovarian ectopic pregnancy relate to the role of IUCD ${ }^{(4,125.6)}$ and the observation that the right ovary is more usually involved ${ }^{(12)}$.

\section{REFERENCES}

1. The report on the Confidential Enquiries into Maternal Deaths and Child Health (CEMACH) in the United Kingdom. Why women die? 2000-2002. London: Department of Health; 2004

2. The report on the Confidential Enquiries into Maternal Deaths (CEMD) in the United Kingdom. Why women die? 1997-1999. London; Department of Health; 2002

3. Grimes HG, Nosal RA, Gallagher JC. Ovarian pregnancy: a series of 24 cases. Obstet Gynecol $1983 ; 61(2): 174-80$

4. Raziel A, Golan A, Pansky M, Ron-El R, Bukovsky I, Caspi E. Ovarian pregnancy: a report of twenty cases in one institution. Am J Obstet Gynecol 1990;163(4 Pt 1):1182-5

5. Seinera P, Di Gregorio A, Arisio R, Decko A, Crana F. Ovarian pregnancy and operative laparoscopy: report of eight cases. Hum Reprod 1997;12(3):608-10

6. Xie PZ, Feng YZ, Zhao BH. Primary ovarian pregnancy. Report of fifteen cases. Chin Med J (Engl) 1991;104(3):217-20 
7. Honigl W, Reich O. Vaginal ultrasound in ovarian pregnancy. Ultraschall Med 1997;18(5):233-6. German

8. Einenkel J, Baier D, Horn LC, Alexander $H$. Laparoscopic therapy of an intact primary ovarian pregnancy with ovarian hyperstimulation syndrome: a case report. Hum Reprod 2000;15(9):2037-40

9. Shamma FN, Schwartz LB. Primary ovarian pregnancy successfully treated with methotrexate. Am J Obstet Gynecol 1992;167(5):1307-8
10. Chelmow D, Gates E, Penzias AS. Laparoscopic diagnosis and methotrexate treatment of an ovarian pregnancy: a case report. Fertil Steril 1994;62(4):879-81

11. Spiegelberg O. Zur casuistic der ovarialsch wangerschaft. Arch Gynakol 1878;13:73-6

12. Rivera FH, Torres FJ, Rodriguez AF. Ovarian pregnancy; a clinicopathological study of eight cases. Eur J Obstet Gynecol Reprod Biol 1988;29(4):339-45. Review

\section{NEWS \& NOTES}

\section{LANCASTER MEDICAL BOOK CLUB}

This historic club was founded in 1823 for the medical gentleman residing in the Lancaster district. Each member paid one guinea per year commencing on St Luke's Day (18th October) for the purchase of books; each half-year the books were sold among the members at half-price and the proceeds used to purchase more books the following year.

By 1827 the social aspect of the club was flourishing with regular meetings and supper, usually at a local inn. In 1841 a medical library was formed in the committee room of the Royal Lancaster Infirmary (RLI) where the books were then kept. From 1877 meetings were held for discussion of professional subjects and in 1966 the RLI Postgraduate Medical Centre was set up, which became the new Education Centre in 2004.

The present-day book club is still thriving with over 200 members. It is open to any doctor living in the Lancaster district at the princely sum of $£ 10$ per year. At our last meeting 84 members and guests attended a very enjoyable dinner followed by a gruesome account of the murders committed by a previous book club member, Dr. Buck Ruxton, who was once a GP in Dalton Square.

Forthcoming events for 2005 are:

Oct 14th - Annual Dinner

Nov 11th - Talk on Richard Owen by Dr Alan Chapman

This year's committee is:

President - Dr Paul Bates

Secretary - Mr Ian Crighton

Treasurer - Dr Andrew Gallagher

\section{GEORGE CUP RESULT 2005}

This year's George Cup Golf Competition was held on Saturday, 25th June 2005 at Morecambe Golf Club. As usual, there was an impressive turnout with 33 golfers playing.

The competition results are as follows:

\section{The George Cup \\ Dr Colin Brown 44 points \\ Dr Andrew Whitton 39 points \\ Mr John Cherry 33 points}

The John Wilkie Quaiche

Dr Hugh McKinney 15 points

The Phil Allen Plate

Mrs Angela Cherry 31 points

The Freend's Silla

Mr Jim Leach 36 points

Congratulations to all players, especially Hugh McKinney. It just goes to show that you can still win the competition at any age!

Andrew Whitton

Golf Secretary

\section{6th ENT study Half-Day}

Organised by Mr M Baraka

Consultant Surgeon ENT

Royal Lancaster Infirmary

A decade of experience in paediatric otolaryngology

With guest speaker

Mr Ray Clarke

Consultant in Paediatric ENT

Alder Hey Hospital, Liverpool

\section{Provisional date for your diary}

11th November 2005 